Invited commentary

\title{
Remarks to the recent trends in exploring medicinal plant diversity
}

\author{
Habil Akos Mathe \\ Department of Botany, Széchenyi University, Faculty of Agriculture and Food Science, Mosonmagyaróvár, Hungary
}

Received November 2, 2018: Revised December 17, 2018: Accepted December 20, 2018: Published online December 30, 2018

\section{Introduction}

Medicinal plants constitute an important part of the natural wealth of mankind. The rich and versatile history of medicinal and aromatic plant (MAP) utilization dates back to the beginnings of our recorded history, since already our forefathers used plants and natural substances they could find in nature to ease and cure their sufferings and illnesses and to heal their wounds.

The dependence on MAPs has survived in the form of traditional medicine (TM) until today, as according to assessments, nearly $80 \%$ of the world population still relies on MAPs in their medications. The greater part of traditional therapy involves the use of plant extracts or their active principles (Akerele and Heywood, 1991). It should be noted that quasi as a contrast, in the high-income countries of the world, the modern renaissance of MAP use has brought about a different type of use, i.e., the use of MAPs in the form of herbal medicines (Complementary/Alternative Medicine (CAM)). In the United States, about 118 of the top 150 prescription drugs are based on natural sources (Balunas and Douglas Kinghorn, 2005).

\section{Global inventory of MAPs}

The exact number of plant species used for medicinal purposes is not exactly known, it can only be estimated. According to Schippmann et al. (2002), this number amounts to more than 50,000 species. Table 1 compares the number of MAP species to the total number of plant species in the flora of relevant countries.

According to a recent assessment by Chen et al. (2016), over 1300 medicinal plants are used in Europe: $90 \%$ of these are harvested from wild resources.

\section{Biodiversity Hotspots}

Earth's biodiversity is in trouble, so is the natural diversity of MAPs. According to Russell A. Mittermeier et al. (2011), there are several factors that threaten the viability of wild populations: invasive species wreak havoc on ecosystems, chemical pollution alters biochemical processes in the soil, air, and water, and rapidly spreading diseases, ultimately jeopardizing entire branches of the tree of life.

Extinction is considered to be the gravest consequence of the biodiversity crisis, since it is irreversible. With the vanishing of species, so does vanish the health security of every human. MAPs

Author for correspondence: Dr. Habil Akos Mathe

Professor, Department of Botany, Széchenyi University, Faculty of Agriculture and Food Science, Mosonmagyaróvár, Hungary

E-mail: acatius2005@gmail.com; akos.mathe@upcmail.hu

Copyright@ 2018 Ukaaz Publications. All rights reserved.

Email: ukaaz@yahoo.com; Website: www.ukaazpublications.com mean a vast genetic storehouse that may harbor a remedy for numerous known or the next new pathogens/cures awaiting to be discovered. It is estimated that compounds initially derived from wild species account for more than half of all commercial medicines, even more in developing nations (Chivian et al., 2008).

Table 1: Number of medicinal plant species used for medicinal purposes (Source: Schippmann et al., 2002)

\begin{tabular}{|l|c|c|c|}
\hline Country & $\begin{array}{c}\text { Plant } \\
\text { species }\end{array}$ & $\begin{array}{c}\text { Medicinal } \\
\text { plant species }\end{array}$ & \% \\
\hline China & 26092 & 4941 & 18.9 \\
India & 15000 & 3000 & 20,0 \\
Mndonesia & 22500 & 1000 & 4,4 \\
Nepal & 15500 & 1200 & 7,7 \\
Pakistan & 4950 & 700 & 10,0 \\
Philippines & 8931 & 300 & 6,1 \\
Sri Lanka & 3314 & 550 & 9,5 \\
Thailand & 11625 & 1800 & 16,8 \\
USA & 21641 & 2564 & 11,8 \\
Viet Nam & 10500 & 1800 & 17,1 \\
\hline Average & $\mathbf{1 3 6 6}$ & $\mathbf{1 7 0 0}$ & $\mathbf{1 2 , 5}$ \\
\hline World & $\mathbf{4 2 2 0 0 0}$ & $\mathbf{5 2 8 8 5}$ & \\
\hline
\end{tabular}

Putting an end to global biodiversity loss requires that limited available resources be guided to those regions that need it most. To achieve this, the concept of Biodiversity Hotspots has been developed (Russell A. Mittermeier et al., 2011). Presently, globally a total of 35 regions meet the hotspot criteria, each holding at least 1,500 endemic plant species (many of them MAPs) and each having lost $70 \%$ or more of its original habitat extent.

\section{"Saving lives by Saving Plants" - The Chiang Mai Declaration}

Reaffirming the WHO/IUCN/WWF commitments to the collective goal of "Health for All by the year 2000", it was the International Consultation on Conservation of Medicinal Plants held in Chiang Mai, Thailand, in 1988, that declared alarm at the consequences of the loss of plant diversity around the world. In the so called Chiang 
Mai Declaration, it expressed the urgent need for international cooperation and coordination to establish programmes for the conservation of medicinal plants to ensure that adequate quantities are available for future generations (WHO et al., 1993).

The decades after the Chiang Mai Declaration (1988) have been marked by several declarations and sets of recommendations calling for the Conservation and Sustainable use of biodiversity including also medicinal plants. Among these, The Convention on Biological Diversity (CBD), an international, legally binding treaty reached at the Earth Summit, in Rio de Janeiro (1992), established the following main goals: the conservation of biological diversity, the sustainable use of its components, and the fair and equitable sharing of the benefits from the use of genetic resources (Diversity, 1992; Cunningham, 1993).

As hardly $10 \%$ of the raw materials comes of cultivation, the significance of cultivation has been stressed, since it offers some important advantages, like: steady sourcing of raw materials, reliable botanical identification/lower risk of adulteration, superior quality (selection of genotypes with desirable traits), controlled postharvest processing, as well as quality control. In cultivation, products standards/regulations/consumer preferences can be more easily observed. Cultivation can meet the requirements of various Good Production Practices (Good Agricultural/Collection Practice, Organic Production Practice) as well as Standards (e.g.: Fair Wild Standard). Ultimately, certification of plant materials produced according to good standards implies possibility for value addition, an option to achieve higher incomes.

In the case of wild sourced MAPs, in harmony with the Good Collection Practices (GCP), the more lately elaborated Fair Wild Standard recognizes that the diminishing availability and loss of MAP wild resources threatens health and economies on a broad scale and undermines the livelihoods of collectors who often belong to the poorest social groups in the countries of origin. Therefore, ecological, social and economic objectives must be met, and best practices must be defined to make plant wild collection sustainable, at the same time ensuring benefits for collectors and their communities (WHO et al., 1993) and (FWF, 2010).

\section{MAPs as industrial products}

MAPs have become "industrial products" with new concepts, like phytotherapy and veterinary medicinal uses, aromatherapy, nutraceuticals, cosmeceuticals, and animal welfare uses, etc., that have been constantly widening the scope of their utilization (Máthé, 2015).

New, innovative, value-added applications include not only human nutrition (e.g.: functional foods) and animal husbandry (e.g.: phytogenic feed-additives) but also the use of MAPs in plant protection (e.g.: in agriculture). In this respect, especially the versatile forms of utilization of essential oils is promising.

\section{MAPs as sources of lead compounds}

MAPs will also maintain their importance in the search for new natural substances and will remain valuable sources of 'drugs and lead compounds'. According to Newman et al. (2003), in the period 1981-2014, the number of all new approved drugs amounted to 1562. Their distribution according to the categories in the genesis of codes elaborated by authors is given in Figure 1.

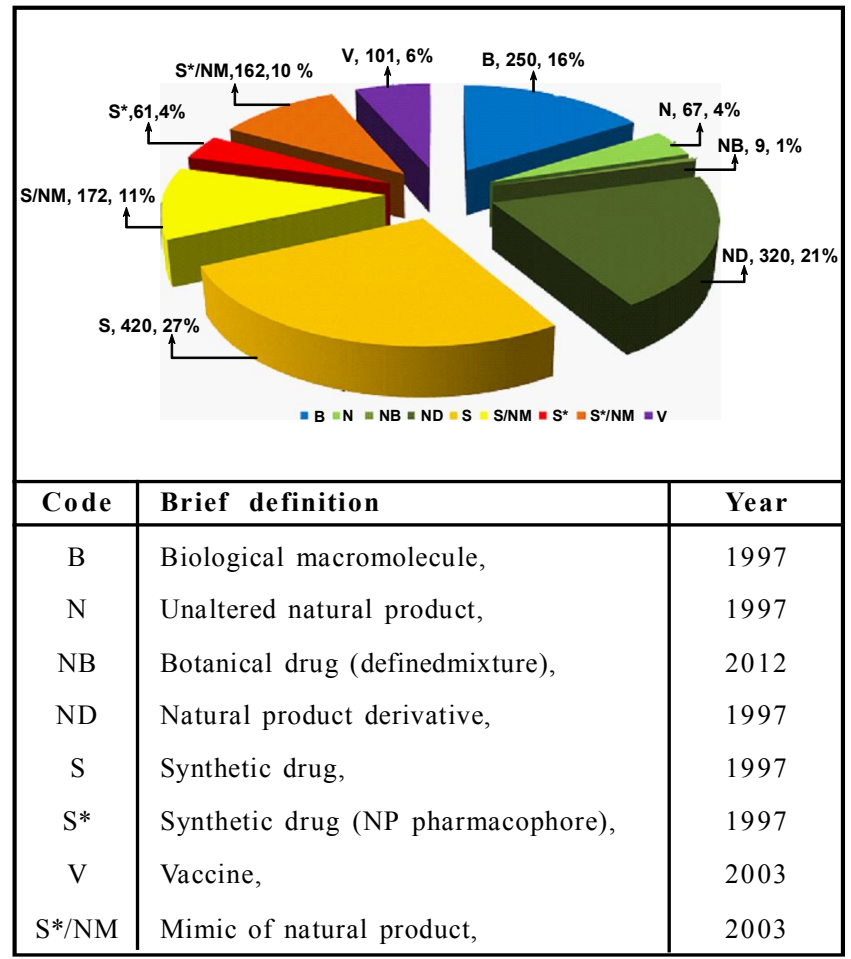

Figure 1: Natural products as sources of new drugs from 1981 to 2014 (Source: Newman et al., 2003).

\section{Quality, safety and efficacy}

The complex and multiple modern approaches in production and uses have brought about an increased focus on the importance of quality, safety, and efficacy issues of both MAPs and their produce (Akerele and Heywood, 1991; Máthé, 2015), etc. In this process, both 'traditional' and cutting edge scientific technologies and methods are deployed.

Quality assurance in Good Agricultural and Collection Practices (GAP) is generally, accomplished through the documented and conscientious implementation of methods and techniques generally already known by stakeholders of the production chain.

The pursuit to better meet 'safety and efficacy' requirements of use has been triggered by a nearly unprecedented progress in the development of new methods/techniques in phytotherapy. This process has been accompanied also by the evolution and application of new comprehensive scientific disciplines, technology platforms (e.g.: "Omics" technologies).

These methods seem to be suitable to substantially improve the simultaneous detection of intrinsic traits of plants, e.g.: proteins/ genes. As a result, the 'high-throughput technologies' (the so called "-omic-" technologies), may open up new horizons in evidencebased phytotherapy research and ultimately, might also lead to a change of paradigms towards the application of complex mixtures in medicine (Mukherjee et al., 2016).

\section{Prevention of botanical adulterations}

Adulteration of botanical ingredients, either accidental or deliberate, can be frequently traced back to poor quality-control procedures. 
Intentional adulteration of plant-based products can lead to unjustified financial advantage. Internationally, there is an increasing awareness about adulteration of botanicals. Phytochemical/genetic analytical and identification methods as well as principles are being elaborated in order to combat adulterations, to minimize this problem.

In the European Union, the Committee on Herbal Medicinal Products (HMPC) of the European Union's Medicines Agency (EMEA) has been engaged in elaborating a Guideline on the specifications: test procedures and acceptance criteria for herbal substances, herbal preparations and herbal medicinal products/ traditional herbal medicinal products (Medicines Agency, 2018). This Guideline addresses 130 specifications, i.e., tests, procedures, and acceptance criteria used to assure the quality of the 131 herbal substances/preparations as well as of HMPs at release and during the shelf-life.

Overseas, in the United States, in 2011, three leading non-profit organizations initiated a large-scale Botanical Adulteration Prevention (BAP) program with the aim of educating members of the herbal and dietary supplement industry about ingredient and product adulteration (Anon, 2018). The BAP is keeping the information current and allow interested parties to access programrelated documents (e.g.: an on-line library of Bulletins, News and other resources).

\section{Phytochemical and genetic identification of plant raw materials}

Normally, plants used as drugs, dietary supplements and/or herbal medicines, etc., are most frequently identified at the species level. It is general practice that phytochemical and genetic data are correlated (although only the latter normally allow for exact differentiation at the species level).

The 'phytochemical' study of MAPs, including the exploration of unknown substances, is assisted also by the new, previously highlighted techniques. Metabolomics is a modern "omic" technique for the comprehensive analysis of phytochemicals. This type of comprehensive analysis can be a valuable tool for identifying potential biomolecules from medicinal plants (Mukherjee et al., 2016).

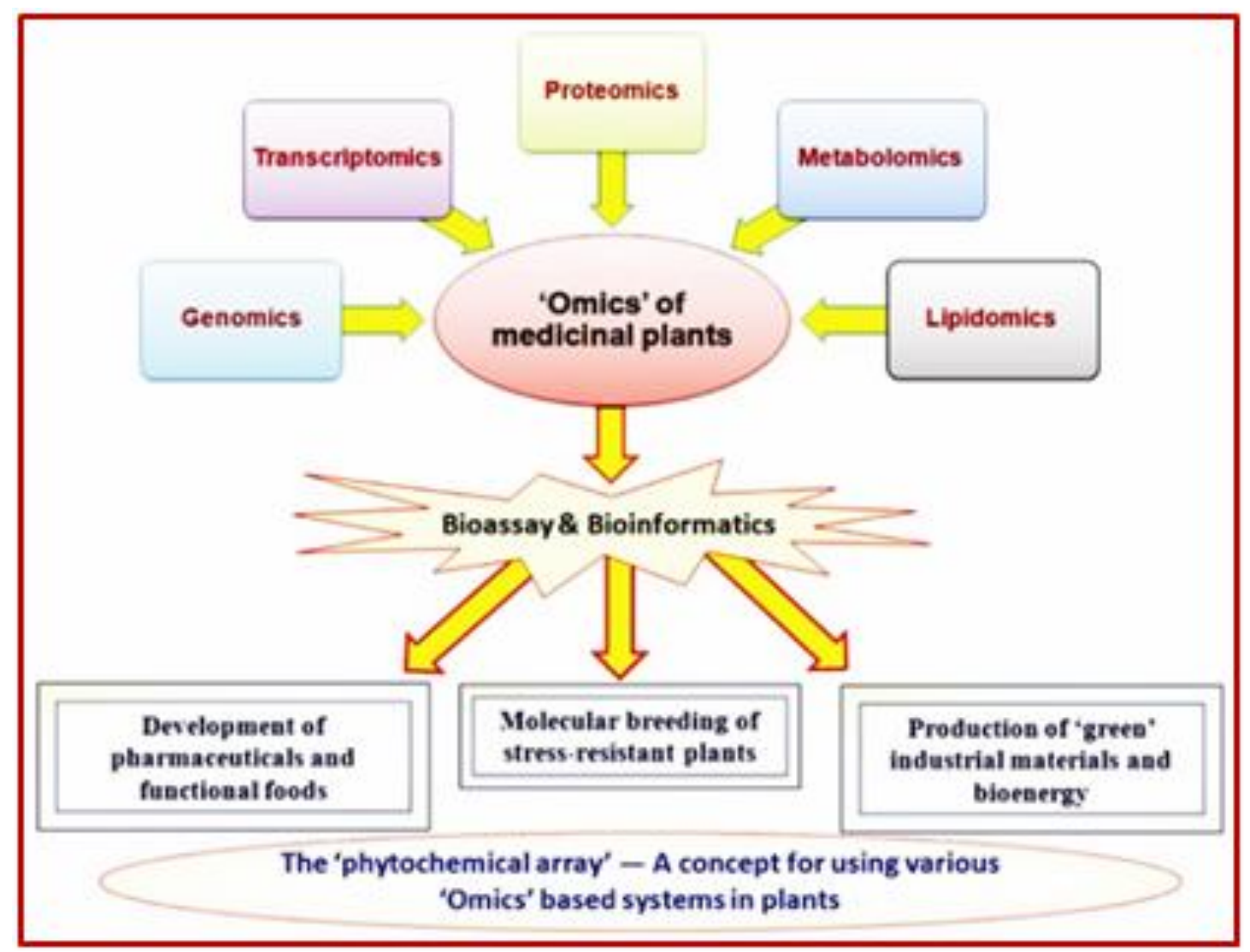

Figure 2: Various phytochemical techniques used in the field of medicinal plant research (Mukherjee et al., 2016).

Unequivocal identification is a critical step at the beginning of an extensive process of quality assurance. It is of importance for the characterization of the genetic diversity, phylogeny and phylogeography as well as the protection of endangered species. DNA-based methods have been developed also for the identification of MAPs. An overview of some important methods according to Sucher and Carles (2008) is given in Table 2. The generation of molecular "barcodes" for every species of medicinal plants on earth is expected to offer a solution to most identification issues.

\section{The role of information and education}

Ensuring safety in the use of MAPs and remedies derived from them requires not only measures for control but also a substantial effort in public information and professional education to make readily 
available up-to-date authoritative data on their beneficial properties and possible harmful effects (Akerele and Heywood, 1991).

Table 2: Some molecular biological methods used for the authentication of MAPs (Pulok K. Mukherjee, Ranjit K. Harwansh, Shiv Bahadur, Sayan Biswas, Lalitha N. Kuchibhatla, 2016).

\begin{tabular}{|l|r|}
\hline \multicolumn{1}{|c|}{ Name } & Acrony m \\
\hline Polymerase chain reaction PCR & PCR \\
Allele-specific diagnostic PCR & \\
Amplification refractory mutation system & ARMS \\
Amplified fragmented length polymorphism & AFLP \\
Arbitrarily primed PCR & AP-PCR \\
Direct amplification of length polymorphism & DALP PCR \\
Multiplex PCR & PCR \\
PCR-selective restriction & PCR-SR \\
Randomly amplified polymorphic DNA & RAPD \\
Sequence characterized amplified region & SCAR \\
Restriction length polymorphism & RFLP \\
DNA microarray & \\
DNA sequencing & \\
Inter simple sequence repeat-anchored PCR & ISSR-PCR \\
Multiplex amplification refractory mutation system & MARMS \\
\hline
\end{tabular}

By publishing and disseminating the innovative findings on MAPs and natural products, covering a broad choice of pharma-related disciplines (e.g.: pharmacognosy, phytopharmacology, phytotherapy, phytochemistry, phytopharmaceuticals, etc.) and also their related aspects, the International Journal, 'Annals of Phytomedicine' has also an important role to play.

\section{References}

Akerele, O. and Heywood, V. (1991). Conservation of medicinal plants Available at: https://books.google.com/books? hl=hu \& $1 \mathrm{r}=\& \mathrm{id}=$ mZZOAAAAIAAJ \&oi $=$ fnd $\& p g=$ PR $11 \& d q=$ guidelines + on + the + conservation + of + medicinal+plants \&ots=ouyFrvnIxh\&sig= yxjN13 qyGK75bAgxlcK1hkW19EE [Accessed February 14, 2016].

Anon, Botanical Adulterants Program. Available at:http://cms.herbalgram. org/B A P/index.html? ts=1543166619\&signature= $6 \mathrm{c} 1 \mathrm{c} 845 \mathrm{c} 8 \mathrm{db} 7461 \mathrm{e} 9 \mathrm{a} 60 \mathrm{fdcfa} 64 \mathrm{~d} 70 \mathrm{bc}$ [Accessed November 25, $2018]$.

Balunas, M.J. and Douglas Kinghorn, A. (2005). Drug discovery from medicinal plants. Science Direct, 78(5):431-441. Available at:https://ac.elscdn.com/S0024320505008799/1-s2.0-S0024320505008799. main.pdf?_tid=2eacc757-b6c8-410d-9c3b-8627e76f57b4 \&acdnat $=1 \overline{5} 43207942 \_41 \mathrm{a} 7 \mathrm{ddfc} 087 \mathrm{a} 53 \mathrm{a} 41 \mathrm{~b} 39 \mathrm{a} 6 \mathrm{eaa} 5 \mathrm{c} 3653 \mathrm{~d}$ [Accessed November 26, 2018].

Chen, S.L.; Zhang, H.; Xie, D.J.; Zhang, J.; Zhou, L.; Rothman, A.M. and Stone, GW. (2016). Conservation and sustainable use of medicinal plants: problems, progress, and prospects. Chinese medicine, 11:37. Available at: http://www.ncbi.nlm.nih.gov/pubmed/27478496 [Accessed November 26, 2018].

Chivian, E. and Aaron Bernstein (2008). Sustaining life/ : how human health depends on biodiversity, Oxford University Press. Available at: https://books.google.hu/books? hl=hu \& lr= \&i d=jIc3AwAAQBAJ $\& o i=$ fnd \&pg $=$ PP $1 \& d q=$ Chivian + E,+ Bernstein $+\mathrm{A}+($ eds $)+(2008)+$ Sustaining+life:+how + human + health + depends + on+biodiversity.+ Oxford + University + Press,$+\mathrm{New}+$ York\&ots $=$ SanvS674dJ\&sig $=$ OBT PpobGK8 Ay0C0XFpThuhC0O44\&redir_[Accessed November 26, 2018].

FWF (2010). FairWild Standard. Version: 2.0, FairWild Foundation, Weinfelden, Switzerland.

Máthé, Á. (2015). Botanical Aspects of Medicinal and Aromatic Plants. In: Á. Máthé, ed. Medicinal and Aromatic Plants of the World. Dordrecht: Springer Netherlands, pp:13-33. Available at: http:// link.springer.com/chapter/10.1007/978-94-017-9810-5 2.

Medicines Agency, E. (2018). Guideline on specifications: Test procedures and 6 acceptance criteria for herbal substances 2 , herbal 7 preparations 3 and herbal medicinal products 4 /traditional 8 herbal medicinal products, Available at: www.ema.europa.eu [Accessed November 25, 2018].

Russell A. Mittermeier; Will R. Turner; Frank W. Larsen; Thomas M. Brooks, and Claude Gascon (2011). Global Biodiversity Conservation: The Critical Role of Hotspots. In: Z. F. \& H. J., eds. Biodiversity Hotspots. Berlin, Heidelberg: Springer Berlin Heidelberg, pp:3-22. Available at: https://www.researchgate.net/profile/Frank_Larsen/publication/ 225989074 Global Biodiversity Conservation The Critical Role of Hotspots/ links/0fcfd503c6f3a203f2000000.pdf [Accessed February 5, 2018].

Russell A. Mittermeier; Will R. Turner; Frank W. Larsen; Thomas M. Brooks, and Claude Gascon (2011). Global Biodiversity Conservation: The Critical Role of Hotspots. In Biodiversity Hotspots. Berlin, Heidelberg: SpringerBerlinHeidelberg,pp:3-22. Available at: http://link.springer. com/10.1007/978-3-642-20992-5_1 [Accessed July 30, 2018].

Pulok K. Mukherjee; Ranjit K. Harwansh; Shiv Bahadur; Sayan Biswas and Lalitha N. Kuchibhatla, (2016). Metabolomics of medicinal plants: A versatile tool for standardization of herbal products and quality evaluation of Ayurvedic formulations. Current Science, 111(10):1624-1630. Available at: https://www.researchgate.net/publication/313128720 Metabolomics_of_Medicinal_Plants_-_A_Versatile_Tool_for Standardization _of_Herbal_Products _ and Q Quality _ Evaluation _ of _ Ayurvedic _ Formulations.

Newman, D.J.; Cragg, G.M. and Snader, K.M., (2003). Natural Products as Sources of New Drugs over the Period 1981"2002. Journal of Natural Products, 66(7):1022-1037. Available at: http://pubs.acs.org/doi/ abs/10.1021/np0300961 [Accessed November 4, 2018].

Schippmann, U.; Leaman, D.J. and Cunningham, A.B. (2002). Biodiversity and the Ecosystem Approach in Agriculture, Forestry and Fisheries. Satellite event on the occasion of the Ninth Regular Session of the Commission on Genetic Resources for Food and Agriculture, Rome. Available at: https://www.researchgate.net/profile/ Uwe Schippmann2/publication/265157471 Impact of _Cultivation _ and _ Gathering _ of _ Medicinal _ Plants _ on Biodiversity_Global_Trends_and_Issues/links/553f24 $\overline{\mathrm{b}} 60 \mathrm{cf}$ 294deef7193d9.pdf [Accessed November 24, 2018 ].

Sucher, N. and Carles, M. (2008). Genome-Based Approaches to the Authentication of Medicinal Plants. Planta Medica, 74(6), pp.603623. Available at: http://www.thieme-connect.de/DOI/ DOI? 10.1055/s-2008-1074517 [Accessed November 26, 2018 ].

WHO, IUCN and WWF (1993). Guidelines on the Conservation of Medicinal Plants. The International Union for Conservation of Nature and Natural Resources (IUCN), Gland, Switzerland. Available at: http://apps.who.int/medicinedocs/documents/s7150e/ s7150e.pdf [Accessed August 5, 2017]. 


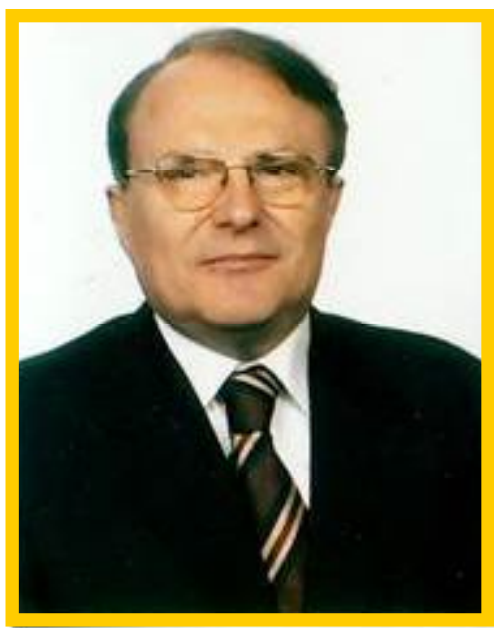

Professor Habil Akos Mathe

Ph.D., Habilitated Doctor, Doctor of Hungarian Academy of Sciences President of International Council for Medicinal and Aromatic Plants (ICMAP)

\section{Biography}

Professor Habil Akos Máthé has a 40 years' background of teaching and research activities in plant ecophysiology, agricultural botany at the University of Horticulture and Food Industry, Budapest and University of West Hungary, Mosonmagyaróvár (legal successor: Széchenyi István University, Gyõr). Retired professor of Botany.

Two times Fulbright Scholar at University of California Davis and University of Massachusetts, Amherst. Visiting professor also at University of Veterinary Medicine, Vienna (Austria). Courses on the production and ecology of Medicinal Plants, as well as Phytogenic Feed Additives, respectively.

Teaching/Research/Consulting and Publication interest and activity include ecophysiology, plant domestication/introduction, production of MAPs, new crops and new uses of plants. International consultant and expertise (e.g.: FAO courses on MAP production Antalya, Turkey, EU COST, IUCN, CBI committees, etc.). Member of editorial board/reviewer of international scientific journals, Ph.D. Theses, etc.
Relevant activities include involvement in both Hungarian and EU funded research projects (e.g.: FEED SEG), education projects (CEEPUS, ERASMUS +, HERB AID, GOOD HERBS, Herbs and Youth, etc.). Founding secretary and member of the Board of Directors of Hungarian Medicinal Plant Association.

Presently, president of International Council for Medicinal and Aromatic Plants (ICMAP http:/www.icmap.org). Chairman of Section for Medicinal and Aromatic Plants, International Society for Horticultural Sciences (2006-2014), Member of Fair Wild Advisory Panel.

He has authored some 100 publications in medicinal and aromatic plant research: series editor, as well as editor/co-author of the monograph series of Medicinal and Aromatic Plants of the World, Springer Science Publishers, The Netherlands (http:// www.springer.com/series/11192).

He has been convener and speaker of several international scientific conferences (ISHS, ICMAP and others), with invited and key note speaker presentations. Network co-ordinator of FAO-related ESCORENA MAP (http://www.agrowebcee.net/map/). 